Original Article

\title{
DEVELOPMENT AND VALIDATION OF STABILITY INDICATING HPTLC METHOD FOR DETERMINATION OF APIXABAN AS BULK DRUG
}

\section{MRINALINI C. DAMLE*, SWAPNIL S. WAGHMARE, PURUSHOTAM SINHA}

Department of Quality Assurance, AISSMS College of Pharmacy, Savitribai Phule University, Kennedy Road, Near RTO, Pune 411001, Maharashtra, India

Email: mcdamle@rediffmail.com

\section{Received: 22 Jun 2018 Revised and Accepted: 29 Mar 2019}

\section{ABSTRACT}

Objective: To develop and validate simple, sensitive stability indicating HPTLC (High performance thin layer chromatography) method for apixaban.

Methods: The chromatographic separation was performed on aluminium plates precoated with silica gel $60 \mathrm{~F}_{254} \mathrm{using}$ toluene: ethyl acetate: methanol (3:6:1 v/v/v) as mobile phase followed by densitometric scanning at $279 \mathrm{~nm}$.

Results: The chromatographic condition shows sharp peak of apixaban at Rf value of $0.38 \pm 0.03$. Stress testing was carried out according to international conference on harmonization (ICH)Q1A (R2) guidelines and the method was validated as per ICH Q2(R1) guidelines. The calibration curve was found to be linear in the concentration range of 100-500 ng/band for apixaban. The limit of detection and quantification was found to be 11.66ng/bandand35.33ng/band, respectively.

Conclusion: A new simple, sensitive, stability indicating high performance thin layer chromatographic (HPTLC) method has been developed and validated for the determination of apixaban.

Keywords: Apixaban, HPTLC, Stability indicating method

(C) 2019 The Authors. Published by Innovare Academic Sciences Pvt Ltd. This is an open access article under the CC BY license (http://creativecommons.org/licenses/by/4.0/) DOI: http://dx.doi.org/10.22159/ijpps.2019v11i5.28071

\section{INTRODUCTION}

Apixaban is an oral anticoagulant and direct inhibitor of factor Xa, which is used to decrease the risk of venous thrombosis, systemic embolization and stroke in patients with atrial fibrillation. Apixaban has been linked to a low rate of serum aminotransferase elevations during therapy and to rare instances of clinically apparent liver injury [1]. Apixaban is chemically described as 1-(4methoxyphenyl)-7-oxo-6-[4-(2-oxopiperidin-1-yl)phenyl]-4,5,6,7tetrahydro-1H-pyrazolo[3,4-c]pyridine-3-carboxamide. Its molecular formula is $\mathrm{C}_{25} \mathrm{H}_{25} \mathrm{~N}_{5} \mathrm{O}_{4}$ and molecular weight is 459.5 (fig. 1) [2].

Apixaban was approved for the prevention of stroke, blood clots in patients with non-valvular atrial fibrillation on December 28, 2012 [3]. On March 142014 it was approved for the use of preventing deep vein thrombosis in adult patients who have undergone total knee or hip replacement surgery [4].

On August 21, 2014, the food and drug administration (FDA) approved apixaban for the treatment of recurring deep vein thrombosis and pulmonary embolism [5]. Apixaban is not official in any of the Pharmacopoeia (USP, BP, EP-checked by online, IP-2014). According to literature survey, there are some HPLC, spectrofluorimetric and HPTLC methods reported for determination of apixaban [6-9] and hyphenated techniques such as LC-MS [10], UHPLC-MS/MS [11], either alone or ina combination tirofiban hydrochloride or with rivaroxaban.

To the best of our knowledge, no stability indicating HPTLC method has been reported for the determination of apixabanas bulk drug. The core-objective of this research work was to develop a simple, accurate, precise, and stability-indicating HPTLC method for the determination of apixaban as bulk drug.

\section{MATERIALS AND METHODS}

\section{Chemicals and reagents}

Apixaban was provided as a gift sample by wockhardt research and development centre, Aurangabad. Ethyl acetate AR grade purchased from FINAR chemicals ltd. methanol, toluene, and all other chemicals used in this study were of AR grade purchased from LOBA chemiepvt. Itd. Mumbai, India.

\section{Instruments}

Linomat-5 sample applicator (Camag, Switzerland), twin trough chamber (10 x $10 \mathrm{~cm}$; Camag, Switzerland), TLC scanner 3 (Camag, Switzerland), WinCATS version 1.4.3 software (Camag, Switzerland), Photostability chamber (Newtronics NEC103RSPI), Shimadzu balance (Model AY-120), Camag100 $\mu$ l sample syringe (Hamilton, Switzerland) were used in the study.

\section{Preparation of standard solutions}

Standard stock solution of apixaban was prepared by dissolving 10 $\mathrm{mg}$ of the drug in $10 \mathrm{ml}$ of methanol to get concentration of $1000 \mu \mathrm{g} / \mathrm{ml}$. From the standard stock solution, working standard solution was prepared containing $20 \mu \mathrm{g} / \mathrm{ml}$ of apixaban.

\section{Selection of analytical wavelength}

The standard solution of apixaban of concentration $10 \mu \mathrm{g} / \mathrm{ml}$ was prepared using methanol and scanned over the wavelength range $200 \mathrm{~nm}$ to $400 \mathrm{~nm}$ by using UV-Visible spectrophotometer. $\lambda_{\max }$ was found to be $279 \mathrm{~nm}$ (fig. 2).

\section{Chromatographic conditions}

Initially, mobile phase optimization trials were conducted using (Chloroform: methanol in the ratios as 5:5, 7:3, 3:7), (Toluene: ethyl acetate-5:5, 7:3, 3:7). Optimized mobile phase was toluene: ethyl acetate: methanol $(3: 6: 1 \mathrm{v} / \mathrm{v} / \mathrm{v})$. TLC plates precoated with silica gel $60 \mathrm{~F}_{254}$, of dimension $10 \mathrm{~cm} \times 10 \mathrm{~cm}$ with $250 \mu \mathrm{m}$ layer thickness were used as stationary phase. TLC plates were pre-washed with methanol and dried. The standard solution of apixaban was spotted on the dried, pre-coated TLC plate as a band with $4 \mathrm{~mm}$ width. The chromatographic development was carried out by using toluene: ethyl acetate: methanol $(3: 6: 1 \mathrm{v} / \mathrm{v} / \mathrm{v})$ as mobile phase with $15 \mathrm{~min}$ chamber saturation time and run up to distance $90 \mathrm{~mm}$. Densitometric scanning was performed at $279 \mathrm{~nm}$. 


\section{Optimization of mobile phase}

Method development for apixaban was started with the development of densitogram using neat solvents and combinations of toluene, ethyl acetate and methanol in different ratios. Toluene: ethyl acetate: methanol in the ratio of $(3: 6: 1 \mathrm{v} / \mathrm{v} / \mathrm{v})$ was selected as mobile phase for apixaban which gives accepted peak parameters. The Rf was found to be $0.38 \pm 0.03$ for apixaban. The standard densitogram of apixaban (200ng/band) is shown in (fig. 3).

\section{Stress degradation studies of bulk drug}

Stress testing studies were carried out to provide evidence on how the quality of drug varies under various stress conditions like oxidation, hydrolysis, photolysis and thermal, etc. Stress degradation studies were designed by referring some papers [12-15]. Optimization of stress conditions was done by changing the strength of reagent and duration of exposure to get 10-30\% degradation. The stress degradation study was carried out as per ICH Q1A (R2) and Q1 B $[16,17]$.

\section{Optimization trials}

Initially trials were conducted using various normalities of $\mathrm{HCl}$ and $\mathrm{NaOH}$ by keeping the sample solution overnight. For the thermal study sample was heated at $80^{\circ} \mathrm{C}$ for $4 \mathrm{~h}$ to $8 \mathrm{~h}$ and for oxidation, trials were conducted using $30 \% \mathrm{H}_{2} \mathrm{O}_{2}$ by keeping the sample solution overnight. It was observed that the drug gets degraded partially.

\section{Optimized stress conditions}

\section{Alkaline hydrolysis}

$1 \mathrm{ml}$ working standard solution of apixaban $(200 \mu \mathrm{g} / \mathrm{ml})$ was mixed with $1 \mathrm{ml}$ of $1 \mathrm{~N} \mathrm{NaOH}$ and volume was made up to $10 \mathrm{ml}$ with methanol. The solution was kept overnight. Average $69.41 \%$ of apixaban was recovered with no peak of degradation.

\section{Acid hydrolysis}

$5 \mathrm{ml}$ standard solution of Apixaban $(200 \mu \mathrm{g} / \mathrm{ml})$ was mixed with 5 $\mathrm{ml}$ of $0.5 \mathrm{~N} \mathrm{HCl}$ and volume was made up to $50 \mathrm{ml}$ using methanol. The solution was refluxed for $30 \mathrm{~min}$ and cooled to room temperature. Average $76.48 \%$ of apixaban was recovered with no peak of degradation.

\section{Oxidative degradation}

$1 \mathrm{ml}$ standard solution of apixaban $(200 \mu \mathrm{g} / \mathrm{ml})$ was mixed with $4 \mathrm{ml}$ $30 \% \mathrm{v} / \mathrm{v} \mathrm{H}_{2} \mathrm{O}_{2}$, volume was made up to $10 \mathrm{ml}$ using methanol. Average $95 \%$ of apixaban was recovered with no peak of degradation after $30 \mathrm{~min}$.

\section{Degradation under dry heat}

Dry heat study was performed by keeping the drug in hot air oven at $80{ }^{\circ} \mathrm{C}$ for $8 \mathrm{~h}$. Average $77.20 \%$ of apixaban was recovered with no peak of degradation.

\section{Degradation under neutral condition}

To $5 \mathrm{ml}$ of $200 \mu \mathrm{g} / \mathrm{ml}$ solution of apixaban, $5 \mathrm{ml}$ of distilled water was added. The volume was made upto $50 \mathrm{ml}$ with methanol. The above solution was refluxed for $2 \mathrm{~h}$ and then cooled. Average $91.48 \%$ of apixaban was recovered with no peak of degradation.

\section{Photo-degradation studies}

Photolytic degradation studies were carried out by exposure of drug to UV light up to 200 watt $\mathrm{h} / \mathrm{m} 2$ and subsequently to cool white fluorescent light to achieve an illumination of 1.2 million Lux $\mathrm{h}$. The sample was weighed, dissolved and diluted get $20 \mu \mathrm{g} / \mathrm{ml}$ as final concentration and was applied to TLC plate. After the photo degradation study under UV light 100\% and Fluorescence light 98.78\% apixaban was recovered with no peak of degradation. Spotting of $2000 \mathrm{ng} / \mathrm{band}$ was done for samples at each stress condition to locate peak for a degradation product if any.

\section{Validation parameter}

The developed method was successfully validated according to the ICH Q2 (R1) guidelines [18].

\section{Specificity}

The specificity of the method was ascertained by analyzing standard drug and sample. The spot for the drug in a sample was confirmed by comparing the Rf and the spectra of the spot with that of the standard drug spot. The specificity of the method was also ascertained by peak purity profiling studies by analyzing the spectrum at peak start, middle and at the peak end.

\section{Linearity and range}

The calibration curve was obtained in the range of $100-500 \mathrm{ng} / \mathrm{band}$ by applying different volumes (5-25 $\mu \mathrm{l})$ of stock solution of $(20$ $\mu \mathrm{g} / \mathrm{ml}$ ) ona TLC plate. Each standard in five replicates was analyzed and peak areas were recorded. The relationship between peak area and concentration was established bythe simple regression equation method (fig. 4).

\section{Assay}

5 tablets were accurately weighed and powdered. From the powder, an amount equivalent to $5 \mathrm{mg}$ of apixaban was accurately weighed and transferred to $10 \mathrm{ml}$ volumetric flask. Methanol was added, sonicated for $15 \mathrm{~min}$, a solution was filtered. Dilutions were made to get the final concentration $20 \mu \mathrm{g} / \mathrm{ml}$. The assay was calculated by extrapolation from standard curve which was found to be $101.02 \%$

\section{Accuracy}

To check accuracy of the method, recovery studies were carried out by adding a standard drug to sample at three different levels 80,100 and $120 \%$. Basic concentration of the sample chosen was $200 \mathrm{ng} / \mathrm{band}$. The drug concentrations were calculated by using the regression equation of apixaban.

\section{Precision}

The precision of the method was demonstrated by intra-day and inter-day studies. In the intra-day studies, 3 replicates of 3 standard solutions were analyzed in a same day and percentage RSD was calculated. For the inter-day, 3 standard solutions were analyzed on three consecutive days and percentage RSD was calculated.

\section{Method sensitivity 'Limit of detection' (LOD) and 'limit of quantification' (LOQ)}

LOD and LOQ were calculated as $3.3 \mathrm{\sigma} / \mathrm{S}$ and $10 \mathrm{\sigma} / \mathrm{S}$ respectively. Where $\sigma$ is the standard deviation of the lowest concentration response and S is the slope of the calibration plot. The LOD and LOQ were found to be11.66ng/band and $35.33 \mathrm{ng} / \mathrm{band}$ respectively.

\section{Robustness}

The robustness of the method were studied during method development, by small but deliberate variations in chamber saturation time $(13,17 \mathrm{~min})$, change in mobile phase composition, Time was changed from spotting to development and development to scanning and the effect on the peak area was noted.

\section{RESULTS}

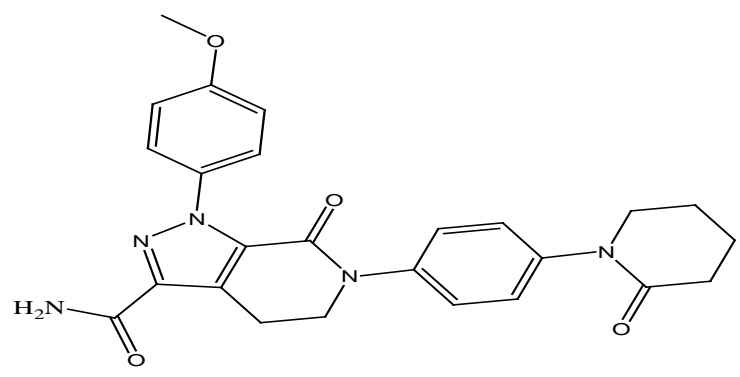

Fig. 1: Chemical structure of apixaban 


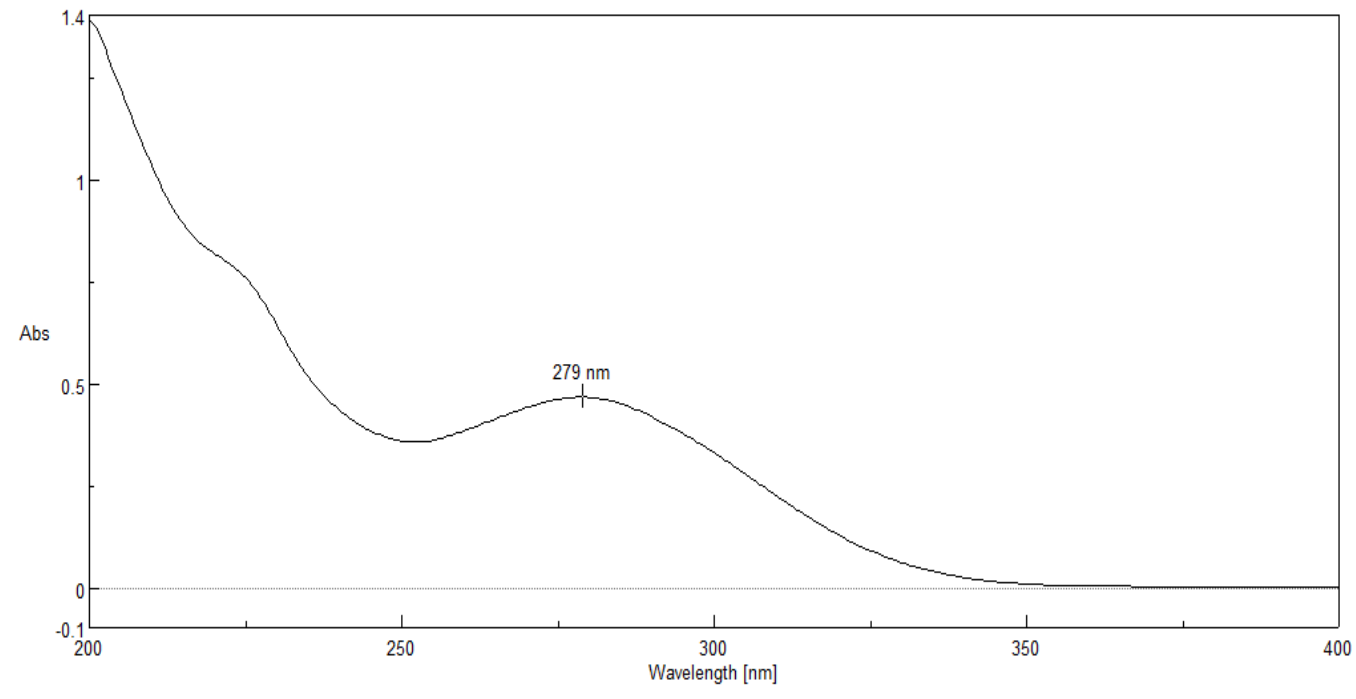

Fig. 2: UV spectrum of apixaban between $200-400 \mathrm{~nm}$

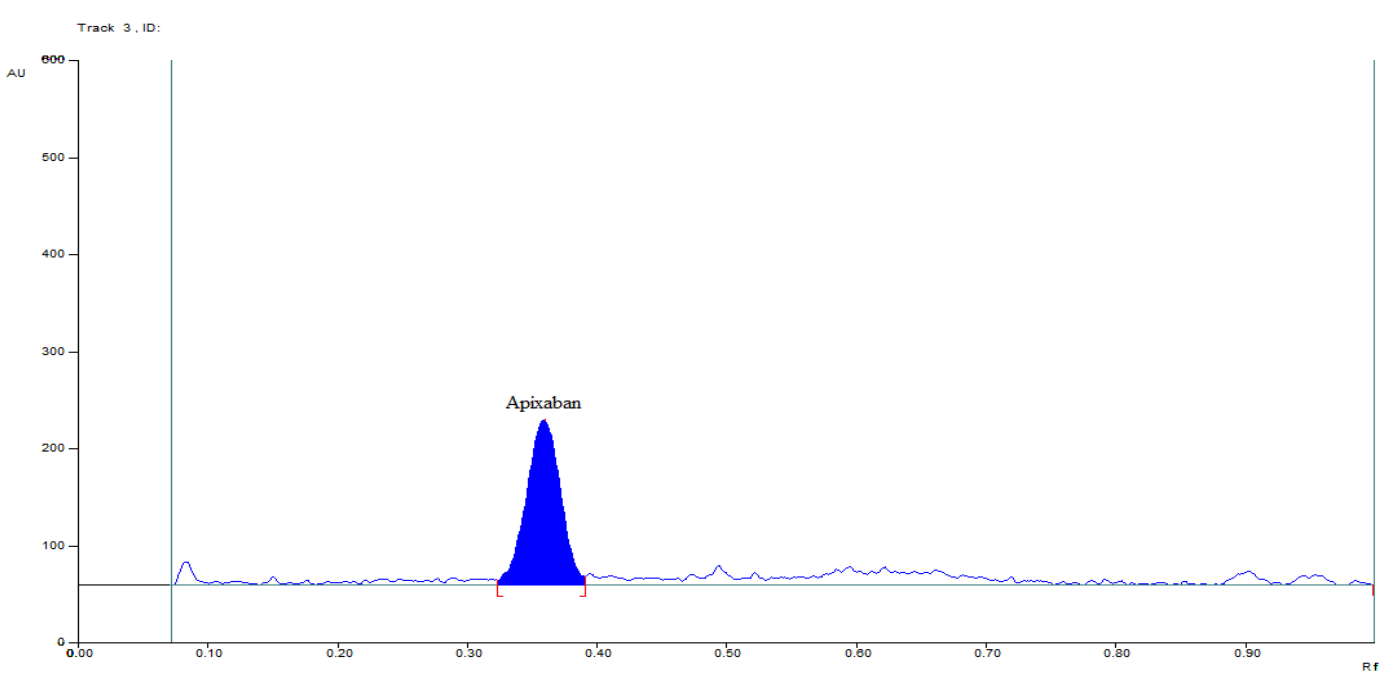

Fig. 3: Densitogram of standard solution of apixaban $200 \mathrm{ng} / \mathrm{band} \operatorname{Rf}(0.38 \pm 0.03)$

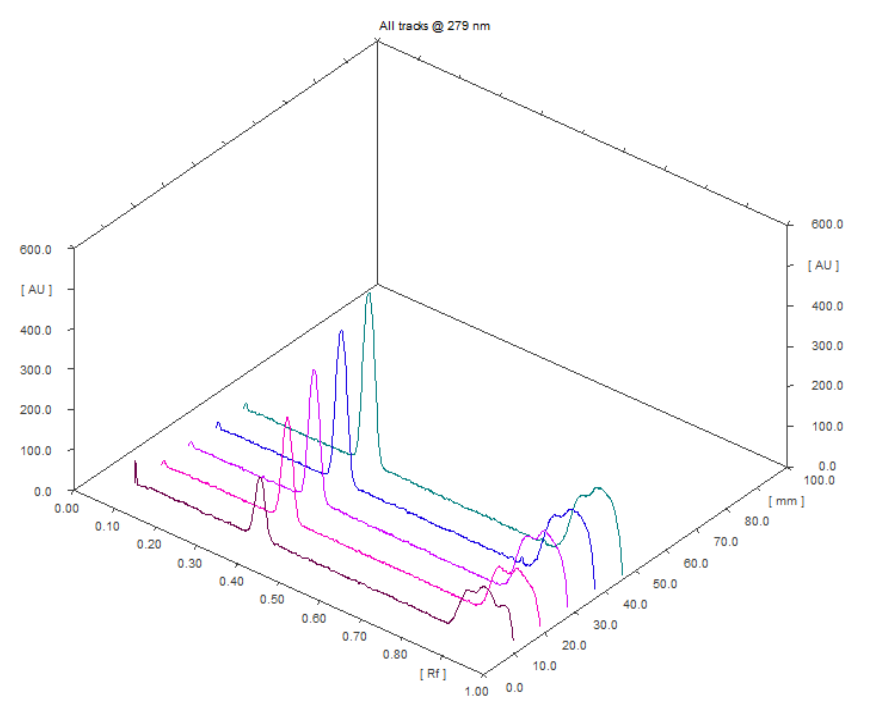

Fig. 4: Densitogram of standard solution of apixaban (100-500ng/band) 


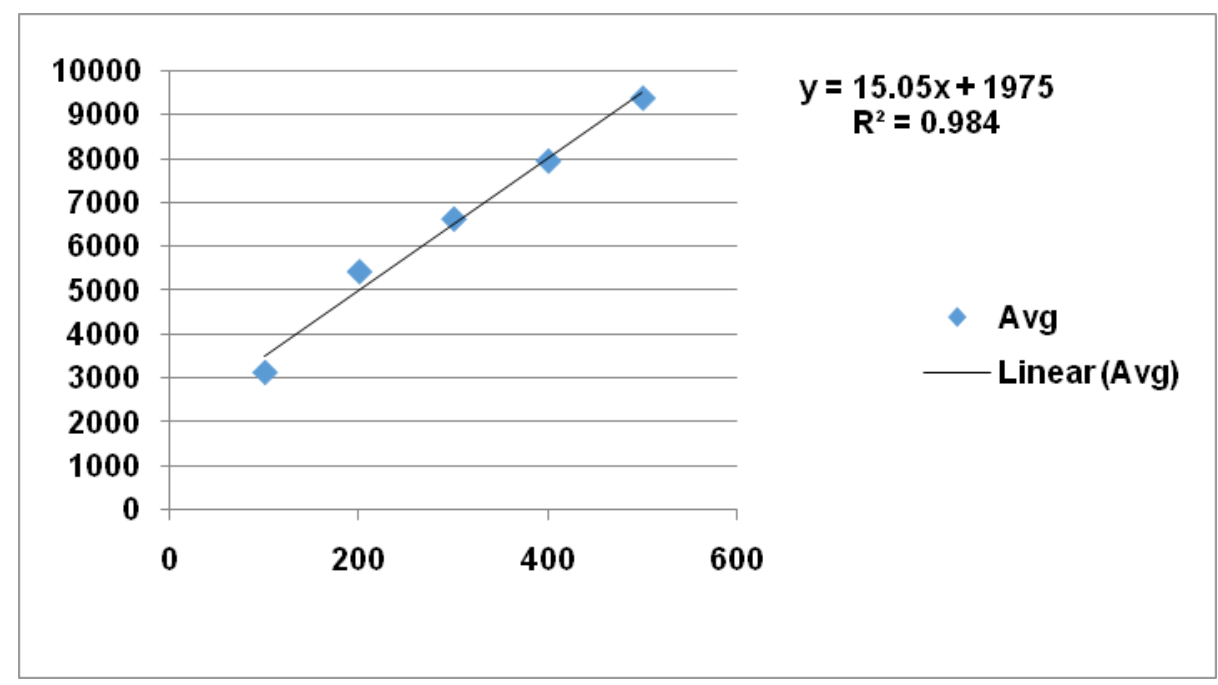

Fig. 5: Calibration curve of apixaban

\section{Stress degradation}

Initially the drug was subjected to various forced degradation conditions. The conditions of stress were optimized with respect to the strength of the reagent and exposure period so as to achieve 10 to $30 \%$ degradation. During optimization, degradation condition was adjusted by the increase and decrease in concentration and strength of reagent and its time of exposure.

Summary of stress degradation results is given in (table 1).

Table 1: Summary of stress degradation study of apixaban $(n=2)$

\begin{tabular}{|c|c|c|c|c|}
\hline \multirow[t]{2}{*}{ Stress degradation condition } & \multirow[t]{2}{*}{ \% Recovery } & \multirow[t]{2}{*}{ \% Degradation } & \multicolumn{2}{|c|}{ Peak purity } \\
\hline & & & $\mathbf{r}(\mathbf{s}, \mathbf{m})$ & $r(m, e)$ \\
\hline Acid $(0.5 \mathrm{~N} \mathrm{HCl})$ reflux for $30 \mathrm{~min}$ & 76.48 & 23.52 & 0.999 & 0.993 \\
\hline Base (1 N NaOH, overnight) & 69.41 & 30.59 & 0.999 & 0.995 \\
\hline Oxidation $\left(30 \% \mathrm{v} / \mathrm{v} \mathrm{H}_{2} \mathrm{O}_{2}\right) 30 \mathrm{~min}$ & 95 & 5.0 & 0.999 & 0.997 \\
\hline Neutral reflux $2 \mathrm{~h}$ & 91.48 & 8.52 & 0.999 & 0.995 \\
\hline Dry heat $\left(80^{\circ} \mathrm{C} 8 \mathrm{~h}\right)$ & 77.20 & 22.8 & 0.999 & 0.998 \\
\hline Photo stability UV 200 watt $\mathrm{h} / \mathrm{m} 2$ & 100 & - & 0.999 & 0.992 \\
\hline Flourescence 1.2 million lux. $\mathrm{h}$ & 98.78 & 1.22 & 0.999 & 0.994 \\
\hline
\end{tabular}

$\mathrm{n}=$ number of determinations for each conditions

\section{Method validation}

Table 2: Result of accuracy (recovery) study of apixaban $(n=3)$

\begin{tabular}{llll}
\hline Concentration (ng/band) & & $\begin{array}{l}\text { Amount } \\
\text { recovered }\end{array}$ & \multicolumn{1}{c}{$\begin{array}{l}\text { \%Recovery } \\
\text { mean } \pm \text { SD }\end{array}$} \\
\hline Sample conc & Amount added & 361.22 & $100.42 \pm 1.32$ \\
200 & 160 & 402.95 & 1.31 \\
200 & 200 & 437.85 & 1.05 \\
\hline
\end{tabular}

$\mathrm{n}=$ number of determinations, $\mathrm{SD}=$ Standard Deviation, $\% \mathrm{RSD}=\%$ Relative Standard Deviation

Table 3: Intra-day precision $(n=3)$

\begin{tabular}{lll}
\hline Concentration (ng/band) & Area (mean \pm SD) & \%RSD \\
\hline 100 & $3120.07 \pm \mathbf{3 9 . 8 2}$ & 1.27 \\
200 & $5409.03 \pm 56.67$ & 1.04 \\
300 & $6629.97 \pm 64.78$ & 0.97 \\
\hline
\end{tabular}

$\mathrm{n}=$ number of determinations

Table 4: Inter-day precision $(n=3)$

\begin{tabular}{lll}
\hline Concentration (ng/band) & Area(mean \pm SD) & \%RSD \\
\hline 100 & $3128.73 \pm 40.76$ \\
200 & $5443.3 \pm 49.74$ & 1.30 \\
300 & $6534.03 \pm 56.37$ & 0.91 \\
\hline
\end{tabular}

$\mathrm{n}=$ number of determinations 
Table 5: Robustness study of apixaban $(n=3)$

\begin{tabular}{|c|c|c|c|}
\hline Parameters & Robust condition & $\begin{array}{l}\text { Area } \\
(\text { mean } \pm S D)\end{array}$ & $\begin{array}{l}\text { \% } \\
\text { RSD }\end{array}$ \\
\hline \multirow[t]{2}{*}{ Chamber saturation time $(15 \mathrm{~min}) \pm 2 \mathrm{~min}$} & $13 \mathrm{~min}$ & $4568.67 \pm 75.51$ & 1.65 \\
\hline & $17 \min$ & $4363.8 \pm 29.84$ & 0.68 \\
\hline \multirow{2}{*}{$\begin{array}{l}\text { Mobile phase composition toluene: ethyl acetate: methanol (3:6:1 } \\
\mathrm{v} / \mathrm{v}) \pm 0.2 \text { methanol }\end{array}$} & Toluene: ethyl acetate: methanol (3:6:0.8) & $4449.4 \pm 49.34$ & 1.10 \\
\hline & Toluene: ethyl acetate: methanol (3:6:1.2) & $4694.67 \pm 54.40$ & 1.16 \\
\hline \multirow[t]{2}{*}{ Time from application to development (immediate) } & After $30 \mathrm{~min}$ & $2872.67 \pm 34.29$ & 1.19 \\
\hline & After $1 \mathrm{~h}$ & $3081.43 \pm 54.52$ & 1.76 \\
\hline \multirow[t]{2}{*}{ Time from development to scanning(immediate) } & After $30 \mathrm{~min}$ & $3068.17 \pm 53.61$ & 1.74 \\
\hline & After $1 \mathrm{~h}$ & $3062.93 \pm 57.66$ & 1.88 \\
\hline
\end{tabular}

$\mathrm{n}=$ number of determinations, $\mathrm{SD}=$ Standard Deviation, $\%$ RSD = \%Relative Standard Deviation

The method validation results were satisfactory as per ICH Q2R1 guidelines. The peak area was found to be linear over the concentration range of $100-500 \mathrm{ng} /$ band with a correlation coefficient of 0.984 . Method specificity can be proved using peak purity parameter in WinCATS software of HPTLC. There is a provision to compare the UV spectrum at the start, middle and end of any peak. Inter and Intra-day precision was less than $2 \%$. Percent recovery in an accuracy study was within the limit of 98 to $102 \%$. The results of validation are summarized in table 6 .

Table 6: Summary of validation parameter

\begin{tabular}{ll}
\hline Validation parameter & Results \\
\hline Linearity & Y $=15.05 \mathrm{x}+1975 \mathrm{R}^{2}=0.984$ \\
Range & $100-500 \mathrm{ng} / \mathrm{band}$ \\
Precision & $(\% \mathrm{RSD})$ \\
A) Intra-day & 1.27 \\
B) Inter-day & 1.30 \\
Accuracy & $(\%$ Recovery) \\
$80 \%$ & 100.42 \\
$100 \%$ & 100.73 \\
$120 \%$ & 99.51 \\
LOD & $11.66 \mathrm{ng} / \mathrm{band}$ \\
LOQ & $35.33 \mathrm{ng} / \mathrm{band}$ \\
Specificity & Specific \\
Robustness & Robust \\
\hline
\end{tabular}

\section{DISCUSSION}

While developing stability indicating method, in the current work, the stress conditions were optimized to achieve $10-30 \%$ degradation. In the literature survey, it observed that the degradation pattern under alkaline hydrolytic conditions reported in work by landge et al. [7] and prabhune et al. [6], do not match at all. Our results fairly match the ones reported by landge et al. except for the degradation product. Apixaban was found to be fairly stable to photo-degradation. Both the reported papers do not have mention of neutral hydrolysis. These papers report Apixaban to be thermally stable but we have observed degradation to an extent of $22.8 \%$

\section{CONCLUSION}

The developed method is simple, sensitive, and precise. No degradation product was observed with the optimized stress conditions. Non-interference has been proved by peak purity studies. Since there is no interference, this method can be used routinely for estimation of apixaban.

\section{ACKNOWLEDGEMENT}

Authors are thankful to the principal and management of the AISSMS College of pharmacy, Pune for providing required facilities for research. Authors are also thankful to the wockhardt pharmaceuticals Pvt. Ltd. Aurangabad for providing an active pharmaceutical ingredient (API) as gift sample.

\section{AUTHORS CONTRIBUTIONS}

All authors have contributed equally to this manuscript

\section{CONFLICT OF INTERESTS}

Declared none

\section{REFERENCES}

1. https: //livertox.nlm.nih.gov [Last accessed on 13 May 2018]
2. https: //rxlist.com [Last accessed on 13 May 2018]

3. http://drugs.com [Last accessed on 13 May 2018]

4. https: //medpagetoday.com [Last accessed on 13 May 2018]

5. https://pfizer.com [Last accessed on 13 May 2018]

6. Prabhune SS, Jaguste RS, Kondalkar PL, Pradhan NS. Stabilityindicating high-performance liquid chromatographic determination of apixaban in the presence of degradation products. Sci Pharm 2014;82:777-85.

7. Landge SB, Jadhav SA, Dahale SB, Solanki PV, Bembalkar SR, Mathad VT. Development and validation of stability indicating RP-HPLC method on core shell column for determination of degradation and process related impurities of apixaban-an anticoagulant drug. AJAC 2015;6:539-50.

8. El-Bagary RI, Elkady EF, Farid NA, Youssef NF. Corrigendum to validated spectrofluorimetric methods for the determination of apixaban and tirofiban hydrochloride in pharmaceutical formulations. Spectrochim Acta A Mol Biomol Spectrosc 2017;174:326-30.

9. Jain HK, Nikam VK. Development and validation of HPTLC method for determination apixaban in bulk and tablets. Int J Appl Pharm 2017;9:78-2.

10. Delavennea X, Mismetti P, Basset T. Rapid determination of apixaban concentration in human plasma by liquid chromatography/tandem mass spectrometry: application to pharmacokinetic study. J Pharm Biomed Anal 2013;78:150-3.

11. Zheng N, Yuana L, Ji QC, Mangus H, Song Y, Frost C, et al. Center punch and whole spot bioanalysis of apixaban in human dried blood spot samples by UHPLC-MS/MS. J Chromatogr B 2015;988:66-74

12. Ashok CV, Sailaja BBV, Pravin KA. Stability indicating reverse phase high performance liquid chromatographic method for simultaneous estimation of labetalol and its degradation products in tablet dosage forms. Asian J Pharm Clin Res 2016;9 Suppl 2:242-9. 
13. Neelima MS, Gandhi BM, Raju VB, Sumanth KR, Srinivas K, Mounika P, et al. Development and validation of stability indicating reverse phase high performance liquid chromatography method for simultaneous estimation of atenolol, hydrochlorothiazide and losartan in bulk and pharmaceutical dosage form. Asian J Pharm Clin Res 2016;9:118-24.

14. Athavia BA, Dedania ZR, Dedania RR, Swamy SMV, Prajapati CB. Stability indicating HPLC method for determination of vilazodone hydrochloride. Int J Curr Pharm Res 2017; 9:123-9.
15. Virani P, Sojitra R, Raj H, Jain V. Chromatographic method for irbesartan and its combination with other drug. J Crit Rev 2015;2:7-11.

16. ICH. Stability testing of few drug substances and products Q1A (R2), International Conference on Harmonisation; 2003.

17. ICH. Harmonized tripartite guideline, stability testing: Photostability testing of new drug substances and products, Q1 (B), International Conference on Harmonisation; 1996.

18. ICH. Validation of analytical procedures: text and methodology Q2 (R1), International Conference on Harmonisation; 2005. 